\title{
عروض مختصرة
}

نصر محمد عارف

1- Christopher Melchert, The Formation of The Sunni School of Law, $9^{\text {th }}-10^{\text {th }}$ Centuries (Leader, Brill, 1997) pp 272.

في محاولة لمناقشة أطروحة المستشرق في جوزيف شاخت حول نشأة المذاهب الإسلامية جاء هذا الكتاب الذي كان أصله رسالة دكتوراه في جامعة بنسلفانيا ليقدم منظورا مختلفا لنشأة المذاهب الفقهية مركزا" على عملية التعليم ونقل المعرفة إلى الطلاب كواحدة من أهم وسائل تأسيس المذاهب الفقهية وعلى الرغم من أنه لم يقدم إجابة على سؤال "لماذا ظهرت المذاهب الفقهية وعلى الرغم من انه لم يقدم إجابة على سؤال "لماذا ظهرت المذاهب الفقهية"، إلا أنه يقدم دراسة مفصلة عن كيفية ظهورها.

2- Richard Yeomams, The story of Islamic Architecture, (London: Garmet Publishing, 1998) pp. 252.

تستطيع العمارة أن تحكي قصة التاريخ. هكذ1 يتخذ مؤلف هذا الكتاب من المسجد الأموي في دمشق مصدرا" لرصد الحياة الاجتماعية والسياسية والثقافية والاقتصادية للمجتمع الإسلامي، و تأثيرها على لى العمارة الإسلامية.

فقد بدأ كتابه بموجة عرض لعقيدة الإسلامية، ثم بعد ذلك ينطلق في عملية متواصلة من موج الفن والعمارة بكل أبعاد الدين الإسلامي حيث يرى أن الابحاهات الدينية حددت وبصورة قوية وظيفة وطبيعة الفن والعمارة الإسلامية. تم بعد ذلك يرصد تطور العمارة الإسلامية من العراق ومصر وتونس حيث التفاعل والتعاطي الدائم. وعند تناوله للحقائق التاريخية والتحديدات والأوصاف الدقيقة للآثار الإسلامية من 
مساجد وأضرحة ومدارس وغيرها ينتقل من شثمال إفريقية إلى وسط آسيا إلى تركيا إلى الأندلس حتى الهند في عرض واف يمثل مقدمة لدراسة العمارة الإسلامية بصورة شمولية.

3- Hasan Kayali, Arabs and Young Truks: Ottomanism, Arabism and Islamism in the Ottoman Empire, 1908-1918 (Berkeley: University of California Press, 1997) pp. 308.

اعتماد على وثائق الأرشيف التركي يقدم المؤلف رؤية مختلفة لنشأة القومية العربية ونظيرها التركية، حيث يرى أن سياسة التتريك التي اتبعتها الدولة العثمانية كانت عرضا للقومية العربية وليست سببا لها، فالقومية العربية نشأت أساسا بدفع من كتابات وآراء معينة في القرن التاسع عشر كان مصدرها السلفيون والعربيون. على حين القومية التركية ظلت محدودة حتى حروب ليبيا والبلقان. في تلك الأثناء انضم أولكك الذين خافوا إضعاف الدولة العثمانية وتدخل الأوروبيون مباشرة فيها إلى ضرب جمعية الاتحاد والترقي على أساس انه سبيل لإعادة مجد الدولة العثمانية. إن هذه الأطروحة تستحق النزر لما تقدمه من رؤية مغايرة تماما لما هو مستقر في الثقافة العربية المعاصرة حول ظهور القومية العربية والعوامل التي رفعت إليه.

4- Azmi Ozcan, Pan-Islamism: Indian Muslims, The Ottoman and Britain (1877-1924) (Leiden: Brill, 1997) pp. 237

يقدم الكتاب أطروحة جديدة حول نشأة فكرة الجامعة الإسلامية حيث يرى أهما فكرة مستقرة في السياسة العثمانية الداخلية والخارجية منذ 1517م وليست من إنتاج جمال الدين الأفغاني والسلطان عبد الحميد كما هو معروف.

ثم يرصد - اعتماد كل مصادر الأرشيف الهندي والباكستاني والتركي - العلاقة بين مسلمي الهند والدولة العثمانية خاصة من مرحلة عبد الحميد الثاني كذلك علاقة المسلمين الهنود بالجماعات التركية القومية 
مثل الاتحاد والترقي. والكتاب يعد دراسة تعتمد على مصادر أولية لفترة من التاريخ الإسلامي المعاصر لا

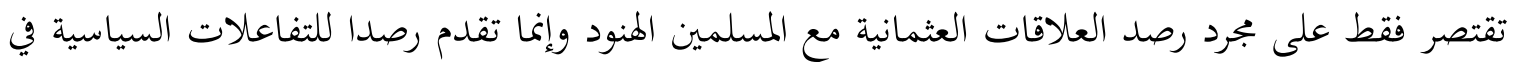
المنطقة في تلك الفترة.

5- Jakob Skovgaard-Petersn, Defining Islam for the Egyptian State: Muftis and Fatwas of the Dar al-Ifta, Social Economic, and Political Studies of the Middle East and Asia (Leiden: Brill, 1997) pp. 431 .

يركز هذا الكتاب على نشأة وتطور دار الإقتاء في مصر وعلاقتها بالدولة منذ خاية القرن التاسع عشر

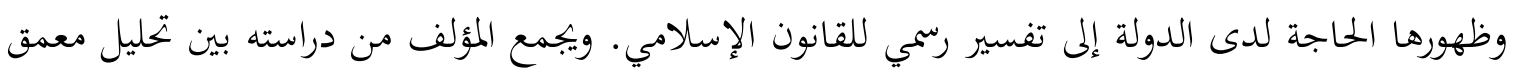

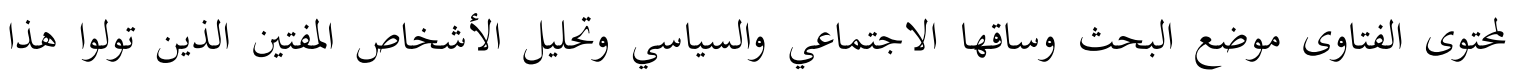
المنصب بمن فيهم محمد عبده الذي كان متعطشا لتكييف القانون الإسلامي للحاجات المعاصرة التي تؤيد وتدعم اهتمامات النخبة المصرية الحديثة. إنه كتاب جديد في موضوعه يستحق التحليل والتقويم ولا سيما أنه يتعرض لواحدة من المؤسسات الإسلامية في الجتمع الإسلامي المعاصر. 